\title{
El color en la reproducción fotográfica en proyectos de conservación
}

José Manuel Santos Madrid | Laboratorio de medios físicos de examen, Centro de Intervención, IAPH

URL de la contribución <www.iaph.es/revistaph/index.php/revistaph/article/view/3511>

\section{RESUMEN}

La fotografía es un medio de indudable valor para registrar información del patrimonio histórico, en el que es fundamental la fidelidad al original. Desde sus inicios se ha convertido en un instrumento clave para la documentación y estudio de los bienes culturales, siendo la reproducción del color uno de sus elementos más relevantes. Se considera necesario establecer métodos de captura y procesado objetivos que incluyan un control de calidad. La preservación de la información colorimétrica contenida en una fotografía digital es una de las contribuciones más notables del medio.

Aunque se han publicado numerosas guías y recomendaciones de buenas prácticas para la digitalización del patrimonio cultural, no existen en el sector unas normas internacionales precisas que establezcan un control de calidad en la producción y conservación de las imágenes. Las Metamorfoze Preservation Imaging Guidelines, que se están implantando sobre todo en el ámbito europeo, son una de las iniciativas en ese sentido.

Siguiendo una metodología precisa y herramientas sencillas al alcance de todos, es posible conseguir que la fotografía digital sirva de salvaguarda de la información colorimétrica, lo que resulta en un valor añadido en su utilización como instrumento de preservación del patrimonio.

\section{Palabras clave}

Color | Colorimetria | Conservación (patrimonio) | Control de calidad | Formato raw | Fotografía digital | Intervención en el patrimonio histórico | Proyecto de conservación | Reproducción de bienes muebles | 


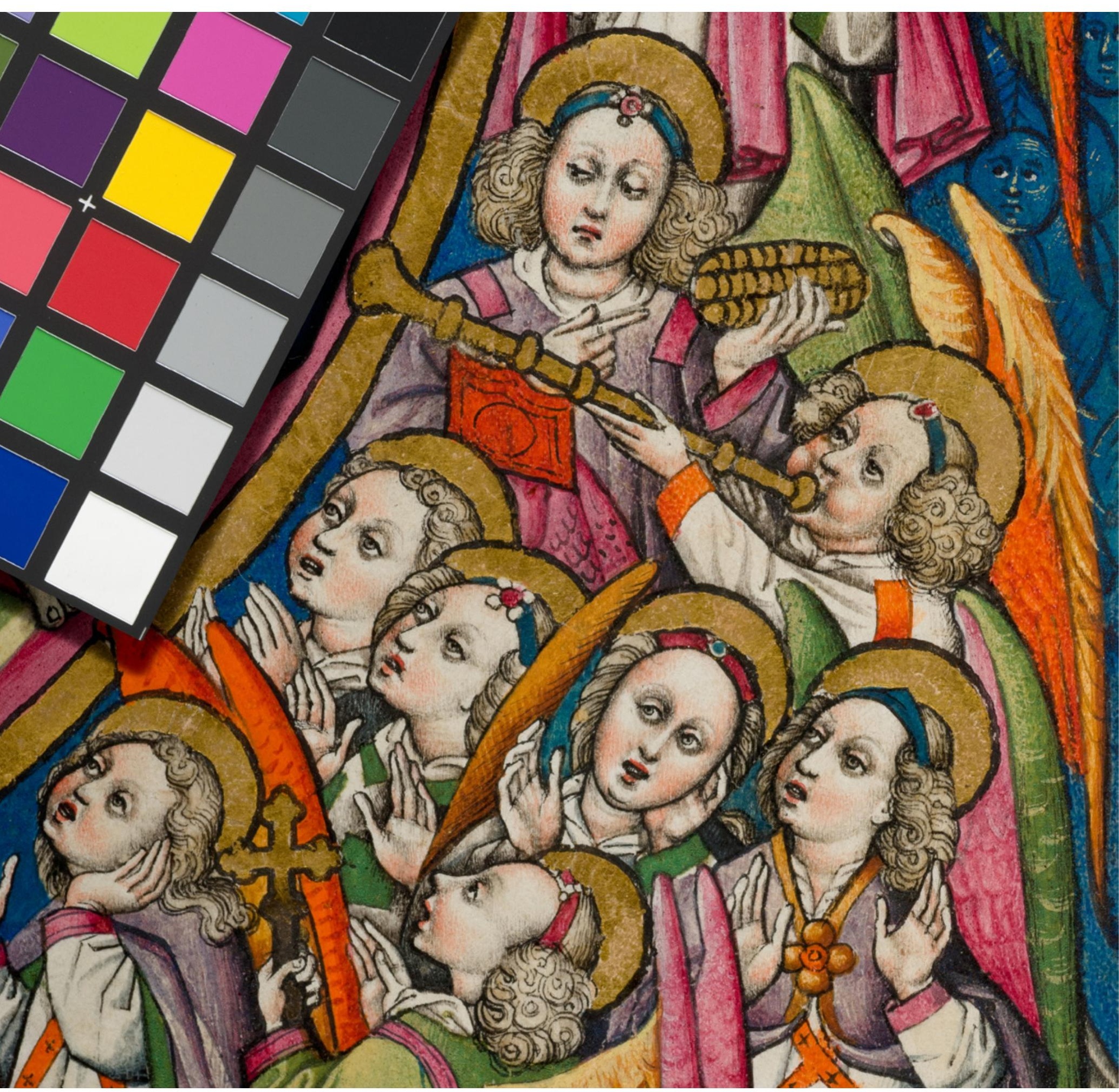

Detalle con carta de color del Libro de Regla de la Cofradía de Ntra. Sra. de las Aguas. Iglesia del Divino Salvador, Sevilla | foto Fondo Gráfico IAPH (José Manuel Santos) para todas las imágenes del artículo, si no se indica lo contrario 


\section{LA FOTOGRAFÍA Y LA PRESERVACIÓN DEL PATRIMONIO}

La fotografía es un medio de indudable valor para registrar información del patrimonio histórico. Documenta su estado en un instante concreto y preserva esa información para las generaciones futuras. Ejerce un papel de testigo, de evidencia de que lo que aparece en la imagen ha existido en algún momento. La fotografía aplicada al patrimonio histórico lleva implícita una presunción de fidelidad al original, hay una confianza previa en que el documento fotográfico es fiable. Esa expectativa de veracidad es, sin duda, un elemento clave que debe ser el principal objetivo en la reproducción fotográfica de bienes culturales.

En el mismo acto de presentación de la fotografía en la Academia de las Ciencias de París, en 1839, ya se vislumbra la utilidad que puede proporcionar en las campañas arqueológicas. Poco después empieza a utilizarse como medio de reproducción de obras de arte y arquitectura. Un hito importante lo marca la Mission Héliographique de 1851, el encargo del gobierno francés a un grupo de fotógrafos de documentar fotográficamente el patrimonio arquitectónico, que supone el reconocimiento de la fotografía como recurso idóneo para la documentación fidedigna (MONDENARD, 1997). Desde entonces, la continua sucesión de técnicas, soportes y formatos han consolidado su aportación a la difusión y al conocimiento del patrimonio.

En la actualidad, la fotografía digital ha acrecentado el papel divulgativo del medio y es ya un instrumento indispensable en la documentación y estudio de los bienes culturales que, en definitiva, redunda en su conservación. Además de facilitar la consulta de piezas o documentos poco accesibles, la imagen digital contribuye a la preservación de originales únicos, frágiles o que están en peligro de desaparición, al evitar la necesidad de su manipulación.

La imagen del patrimonio puede tener fines diversos $y$, por tanto, las expectativas y exigencias de calidad pueden ser diferentes para cada usuario. En este sentido, se ha propuesto un modelo que relaciona la calidad de la imagen con las expectativas que genera, según tres dimensiones: fidelidad, utilidad y naturalidad (modelo FUN de Yendrikhovskij, citado en MACDONALD; JACOBSON, 2006: 354; PEREIRA, 2013: 9) Los conservadores del patrimonio, por ejemplo, necesitan que la reproducción del color sea fiel al original y que la imagen presente un grado de detalle máximo. Para un investigador que consulta un archivo digitalizado, la utilidad esencial es que la imagen permita la legibilidad de los documentos. Los visitantes de un museo que quieren llevarse como recuerdo el cartel de una pintura quedarán satisfechos con una reproducción en la que el color coincida con sus recuerdos, que sea estéticamente agradable y les evoque una grata experiencia (MACDONALD, 2006). 
Una fotografía destinada a conservar información fidedigna de nuestros bienes culturales debe de cumplir con unos criterios de fidelidad definidos, para lo cual es necesario establecer métodos de captura y procesado objetivos que incluyan un control de calidad con estrictos márgenes de tolerancia. Este proceso de validación le otorga a la imagen el valor de documento científico fiable. La necesidad de un consenso en esta materia es tema de un importante debate en el sector.

El color es uno de los elementos que definen un objeto patrimonial, en especial, y como es obvio, en pinturas o esculturas policromadas, aunque también en piezas arqueológicas, cerámicas, mosaicos, documentos manuscritos e iluminados, tapices y otras obras textiles, etc. De ahí que la fidelidad en la reproducción del color haya sido siempre una de las principales preocupaciones de los fotógrafos especializados en la reproducción de obras de arte.

Los medios para garantizar la exactitud de esa reproducción en el mundo de la fotografía química eran escasos: control de la iluminación, fotómetros para establecer la exposición correcta, instrumentos para medir la temperatura de color de las fuentes de iluminación, filtros para compensar las dominantes de color. El control de la fidelidad del color se confiaba en muchas ocasiones a la propia pericia, al criterio subjetivo de la observación visual de las transparencias en mesas de luz, que idealmente contaban con lámparas corregidas de "luz día" o $5.000^{\circ}$ Kelvin. Las diferencias de color entre diferentes marcas o modelos de película, incluso entre lotes distintos del mismo material, se unía a las variaciones en el proceso de revelado producidas por un mínimo cambio de temperatura de los líquidos. Pero quizás la mayor limitación fuera la poca estabilidad de los tintes cromógenos de la mayoría de emulsiones fotográficas en color, aun en las mejores condiciones de conservación (FUENTES, 2000; 2012). Éstas y otras limitaciones de la fotografía analógica impiden mantener una constancia en la reproducción fiel del color.

La transición a la fotografía digital ha supuesto una mejora importante en ese sentido, aunque ha sido necesario un periodo de adaptación por parte de los técnicos a un nuevo medio de reproducción. La inercia puede llevar a mantener algunos métodos de trabajo adquiridos en el mundo analógico y que pueden inducir a errores en la captura digital. Pasar de la selección visual en la mesa de luz a la edición de imágenes en pantalla también "a ojo", supone heredar prácticas que impiden un control colorimétrico preciso.

Las diferencias de color entre imágenes de una misma obra, que podían ser comunes en fotografía química por las razones expuestas, pueden y deben evitarse en fotografía digital aplicada al patrimonio. Esto es más importante, si cabe, en proyectos de restauración en los que una obra sufre variaciones durante el proceso, que deben quedar adecuadamente registradas. 

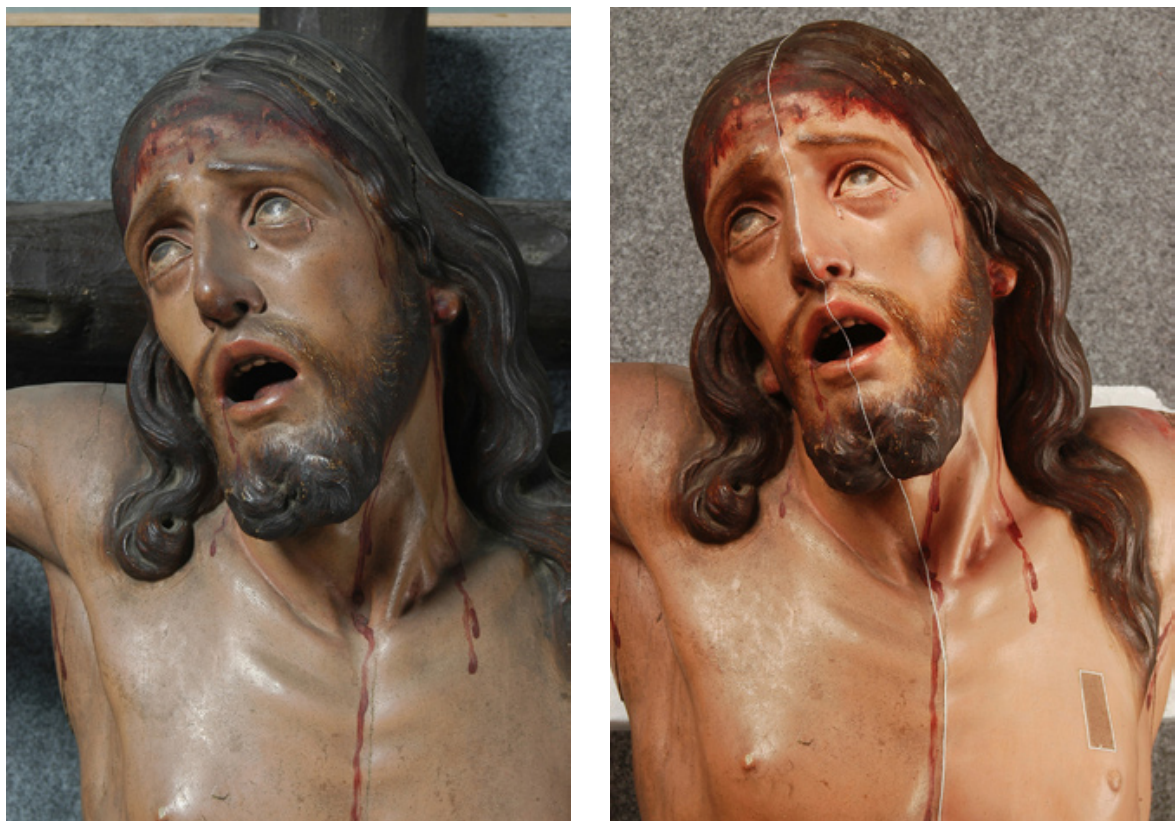

Obviamente, es normal que haya diferencias de tono entre dos imágenes tomadas en distintas fases, que pueden ser debidas, por ejemplo, a la limpieza de un barniz oxidado. Pero no debe caber duda de que ese es el motivo del cambio de color, y no una mala praxis en la captura o procesado de la imagen.

La recomendación general para sacar todo el partido de las cámaras digitales es capturar en formato RAW, un formato de archivo en bruto, sin procesar y propio de cada fabricante, que recoge toda la información que captura el sensor (EVENING, 2013; SCHEWE, 2013). Se suele comparar este formato con un negativo digital, por semejanza con los negativos fotográficos en película. Ambos son un paso intermedio que hay que procesar para la obtención de la copia final. Ansel Adams, un maestro de la fotografía en blanco y negro, creador del sistema de zonas, comparaba el negativo con una partitura musical, y la copia final con la interpretación que se hace de esa partitura (ADAMS, 1999).

La tendencia en los programas de procesado de los archivos RAW es facilitar su edición desde un punto de vista creativo, interpretando el negativo con criterios subjetivos. Pero esa interpretación puede variar de un operador a otro, e incluso un mismo técnico puede producir resultados diferentes en momentos distintos. Cuando se trata de preservar el patrimonio a través de la fotografía, el procesado debería seguir un flujo de trabajo repetible, basado en referencias normalizadas como pueden ser los valores numéricos de las cartas de escala de grises y de color. 
El color puede definirse con números, y una imagen digital es también un conjunto de números. Lógicamente, no se puede concluir que el simple cambio de soporte garantice una reproducción fiel del color. Igual que sucede con las películas fotográficas, cámaras de distintos modelos o fabricantes tienen respuestas espectrales distintas, lo que se traduce en una gama de color propia de cada dispositivo de captura, y los procesos de edición de las imágenes digitales pueden introducir también cambios en el color.

\section{Los nombres del color}

El color se define como una "sensación producida por los rayos luminosos que impresionan los órganos visuales y que depende de la longitud de onda", según el Diccionario de la Real Academia de la Lengua Española. La percepción visual del color depende de la luz que llega a un objeto y de la interpretación individual de ese estímulo por parte del observador. Los términos comúnmente empleados para definir el color hacen referencia a su matiz o tinte rojo, verde, amarillo, azul, naranja o añil; otros atributos del color son su luminosidad o su saturación. La paleta de colores de artistas y restauradores tendrá azul cobalto, siena tostada, carmín o blanco de titanio, que serán sutilmente diferentes según la marca de los pigmentos. Resulta difícil comunicar el color en estos términos, ya que depende del observador definir un tono concreto de rojo o si un amarillo es más o menos luminoso. Es necesario, por tanto, establecer un sistema de referencia que defina el color de forma objetiva (X-RITE, 2002; FRASER; MURPHY; BUNTING, 2005).

Una de las propuestas para describir objetivamente el color es el modelo CIELAB, o $L^{*} a^{*} b^{*}$, un modelo cromático establecido por la Comisión Internacional de la lluminación, $\mathrm{CIE}$ (Commission Internationale de L'Eclairage). CIELAB representa todos los colores que percibe el ojo humano en un espacio de tres dimensiones, donde el eje $L^{*}$ expresa la luminosidad con valores de 0 a 100 , del negro al blanco con toda la escala de grises intermedios, y los ejes $a^{*} y b^{*}$ son valores de cromaticidad: $a^{*}$ es la componente de color rojo o verde $y b^{*}$ la componente de amarillo o azul (PEREIRA, 2013).

Las diferencias entre colores del espacio CIELAB se calculan mediante ecuaciones deltaE o $\triangle \mathrm{E}$. Aunque hay varias fórmulas para calcular las diferencias, las más comunes son la $\Delta \mathrm{E}^{*}$ de 1976 y la ecuación CIE2000 o $\triangle E 00$. Es posible calcular las diferencias en cualquiera de las coordenadas de CIELAB, tanto en luminosidad $\Delta \mathrm{L}^{*}$ como en los canales cromáticos $\Delta \mathrm{a}^{*} \mathrm{y}$ $\Delta \mathrm{b}^{\star}$. Se considera que un valor $\Delta \mathrm{E}^{\star}$ entorno a 3 o 4 indica una diferencia de color inapreciable para el ojo humano. El margen de tolerancia para la fórmula $\Delta \mathrm{E}^{*}$ está normalizado en algunos sectores como las artes gráficas, con un valor máximo permitido de 5 (PEREIRA, 2013). 


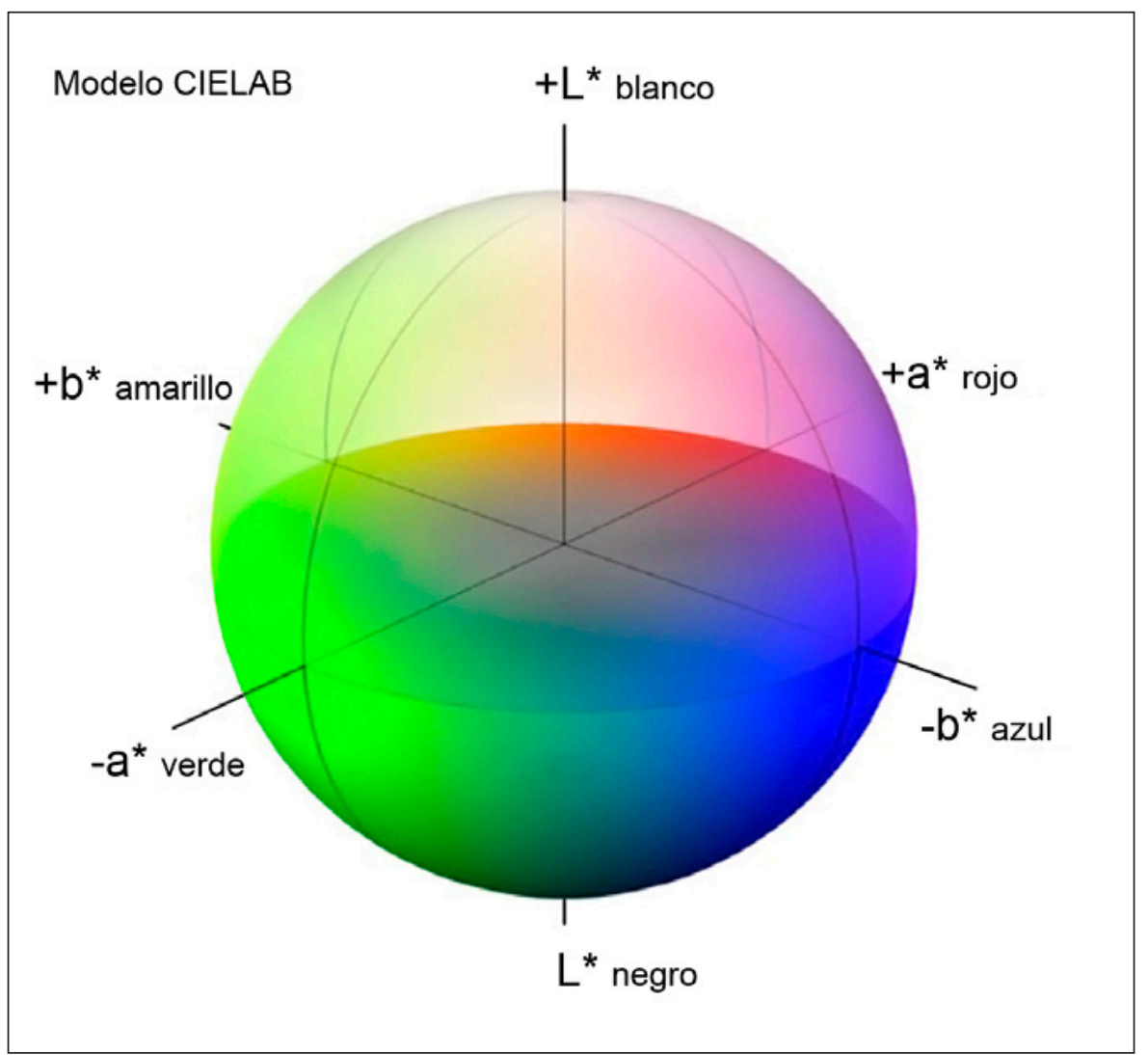

De forma objetiva, el color puede ser analizado por instrumentos cuyo principio básico es medir la cantidad de luz que refleja o transmite un objeto en distintas bandas del espectro visible. Los instrumentos recomendados para medir el color son los espectrofotómetros, que registran la intensidad de la luz en bandas estrechas de longitudes de ondas. Otro tipo de instrumentos son los colorímetros, en los que el espectro visible se divide en tres bandas por filtros de color rojo, verde y azul.

El sensor de una cámara digital convencional también registra la intensidad de la luz del modo en que lo hace un colorímetro, con los filtros rojo, verde y azul integrados en sus fotocélulas. Por tanto, si se conocen las características espectrales o colorimétricas de una cámara fotográfica, podrá emplearse para registrar y medir el color (GREEN, 2006). Para conocer estas características de la cámara hay que proceder a su caracterización o perfilado, que en su forma más sencilla consiste en capturar una carta de color bajo una iluminación determinada e interpretar el resultado mediante software específico. Este tipo de cartas contiene una serie de parches de color cuyos valores son conocidos. Los datos de la imagen se analizan para comprobar las desviaciones de color que se producen respecto al patrón y se crea un perfil, esto es, un archivo de datos numéricos que describe las características del 
dispositivo y su correspondencia con los datos de la carta en un espacio de color establecido, generalmente CIELAB (PEREIRA, 2013).

Se ha propuesto también el registro del color mediante la utilización de cámaras multiespectrales, que capturan imágenes de múltiples bandas estrechas del espectro electromagnético. La información que aportan estos sistemas extiende el rango de longitudes de onda del campo visible al ultravioleta y al infrarrojo. Las imágenes multiespectrales permiten realizar colorimetría de precisión, aunque quizás sea la identificación de pigmentos por la imagen una de sus más interesantes aplicaciones. Sin embargo, se trata de equipos menos extendidos y accesibles que las cámaras digitales convencionales (BERNS, 2005; SAUNDERS; CUPITT; PADFIELD, 2006).

\section{Sistemas de gestión del color}

El objetivo de la gestión de color es controlar que la reproducción del color sea predecible, en un sistema en el que están implicados diferentes equipos. De esto se encarga una serie de aplicaciones y procedimientos para intercambiar la información de color entre dispositivos y mantener una apariencia cromática aceptable. En 1993 un grupo de fabricantes de dispositivos y aplicaciones relacionados con la reproducción del color crearon el International Color Consortium (ICC), con el fin de establecer unas normas de caracterización y concordancia entre equipos en la gestión de color. Las empresas fundadoras de este consorcio son Adobe, Microsoft, Apple, Agfa y Kodak, y se han ido sumando muchas otras. Como resultado se establecieron unas especificaciones que definen el formato de los perfiles de color o perfiles ICC (FRASER; MURPHY; BUNTING, 2005; PEREIRA, 2013; RODNEY, 2005).

El sistema de gestión de color del ICC se basa en la caracterización de dispositivos, que tiene por objeto conocer su espacio de color y generar un perfil. Las imágenes obtenidas con cámaras o escáneres (dispositivos de entrada) se preparan en un espacio de color de trabajo estándar como AdobeRGB, antes de convertirlas a un espacio de color de salida, propio de impresoras o monitores. Este flujo está orientado principalmente a la obtención de un resultado visualmente coherente, ya sea impreso o en pantalla, y es apropiado para cumplir esa función.

Sin embargo, la imagen destinada a la preservación del patrimonio cultural puede tener unos requerimientos más exigentes, en los que el principal objetivo no tiene porqué ser una imagen impresa. El análisis de la información tonal y colorimétrica contenida en una fotografía digital es uno de ellos. En esa línea, puede ser de ayuda la adopción de nuevos espacios de color de gama amplia, orientados a conservar el máximo de información contenida en la escena original. Desde el ICC se ha propuesto un flujo de trabajo para pro- 
DNG es un formato de archivo RAW no propietario propuesto por Adobe Systems para cubrir la ausencia de estándar de los formatos RAW de cámaras digitales. La mayoría de fabricantes de cámaras tienen sus propios formatos RAW y su software de procesado; algunas marcas han optado por DNG como formato RAW nativo de sus cámaras. Adobe ha publicado las especificaciones de DNG, por lo que se considera un formato abierto. También proporciona herramientas para convertir prácticamente cualquier formato RAW propietario en el formato DNG.

\section{2}

ColorCecker es una carta de color fabricada originalmente por Macbeth, actualmente propiedad de X-Rite. La ColorChecker original o Classic es una carta de 24 parches dispuestos en 4 filas de 6 columnas. Las dos primeras filas contienen colores naturales y variados; la tercera representa los colores primarios; la última fila es una escala de grises. Se distribuye en distintos formatos: ColorChecker Classic de unos 21×28 cm; Mini, de 6x11 cm; ColorChecker Passport, un estuche de plástico rígido de 9x12,5 cm que incluye la carta original, otra con colores y grises adicionales con distintas funciones y un gran parche para balance de blancos. Una carta distinta es la ColorChecker SG, con unos 140 parches de acabado semibrillo (PEREIRA, 2013) ducir esa imagen "referida a la escena", con intención colirimétrica, haciendo un revelado RAW neutral con los controles básicos de exposición y tonos puestos a cero (ver www.color.org/scene-referred.xalter).

En los últimos años algunos de los miembros del consorcio han comenzado a lanzar propuestas propias con la idea de mejorar el sistema con nuevos métodos, que pueden integrarse en el flujo del ICC pero que divergen en parte de la convención ya establecida (PEREIRA, 2013). Una de estas iniciativas es el perfilado de cámaras digitales propuesto por Adobe, dentro de la especificación de su propio formato abierto DNG, Digital Negative (ADOBE, 2012) ${ }^{1}$. En lugar de emplear perfiles ICC para caracterizar el equipo de captura, la propuesta de Adobe es crear perfiles de cámara (DNG Camera Profile, DCP). Estos perfiles están indicados para asumir el rango dinámico de una escena real, que puede presentar un contraste mucho más elevado del que es capaz de reproducir cualquier dispositivo de impresión. Los perfiles DCP pueden ser creados a partir de cartas ColorChecker ${ }^{2}$ con la herramienta de Adobe DNG Profile Editor o con la de X-Rite ColorChecker Camera Calibration. Son similares a los perfiles de color del ICC, aunque presentan diferencias en su estructura interna. (PEREIRA, 2013). Aun siendo una creación de Adobe y estar integrado en sus propios sistemas de revelado Camera RAW y Lightroom, gracias a la publicación abierta de sus especificaciones se está extendiendo su uso y se ha ido incorporando en otros programas, algunos de código libre y abierto como RAWTherapee (http:// RAWtherapee.com).

A diferencia de los perfiles ICC, una característica de los DCP es que se pueden crear perfiles con dos iluminantes, es decir, con dos fuentes de iluminación de distintas características y temperatura de color. Esto permite crear un solo perfil que funcionará correctamente aunque cambien las condiciones de iluminación, haciendo necesario solamente ajustar el balance de blancos.

\section{La necesidad de un consenso en el sector del patrimonio}

Atendiendo a las necesidades propias de la digitalización del patrimonio, en los últimos años están surgiendo iniciativas orientadas a buscar un consenso en la adopción de normas, teniendo la fidelidad en la reproducción del color como una de sus preocupaciones. La fotografía es un sector que cuenta con numerosos estándares ISO, pero muchas de estas normas tienen su origen en la fotografía química o están orientadas al control de la imagen digital con destino a la impresión en artes gráficas que, como se ha visto, no cubren todos los requisitos propios del sector.

Diversos organismos e instituciones relacionados con el patrimonio cultural han publicado guías o recomendaciones de buenas prácticas para la 
digitalización de obras de arte, documentos de archivos históricos y otros bienes culturales (por ejemplo www.iaph.es/web/canales/de-interes/mediateca/fondo.html). Esto muestra la preocupación del sector en la necesidad de asegurar la preservación del patrimonio digital, sabiéndose responsable además de que la información que producen y proporcionan al público sea una representación fidedigna de la realidad (ver extensa bibliografía en DIRECTRICES, 2002).

Por encargo de la Unesco, un grupo de expertos redactó en 2002 las Directrices para proyectos de digitalización de colecciones y fondos de dominio público, en particular para aquellos custodiados en bibliotecas y archivos (DIRECTRICES, 2002). Estas directrices reproducen la pauta que siguen otras guías, particularmente las orientadas a la digitalización de documentos mediante escáner. En general, orientan de forma más o menos extensa sobre unos principios básicos en cuestiones de iluminación, calibración y perfilado de los equipos de captura y visualización, formatos de archivos de imagen o metadatos. Todo el proceso está encaminado a la obtención de un archivo de imagen máster de conservación. Sin embargo, las indicaciones acerca del procesado neutro y objetivo de los archivos RAW son escasas o nulas, y el control de calidad en la reproducción del color se reduce, en la mayoría de ocasiones, a recomendar el sistema de gestión promovido por el ICC.

Merece ser destacada la publicación en nuestro país del libro Gestión del color en proyectos de digitalización, de José M. Pereira, que hace un compendio de gran cantidad de información sobre la cuestión del color aplicada al patrimonio. El autor reivindica la imagen digital como herramienta de preservación y propone métodos de control de calidad en proyectos de digitalización; proporciona además en su blog diversas utilidades para la validación de los resultados (www.jpereira.net). Aborda todas estas cuestiones desde un punto de vista realista con la situación tecnológica de la mayoría de profesionales e instituciones dedicados a la protección del patrimonio (PEREIRA, 2013).

El experto en imagen digital Scott Geffert, del Metropolitan Museum of Art de Nueva York, también hace una completa revisión del estado de la cuestión en una serie de artículos y aporta valiosas propuestas encaminadas a ese consenso (GEFFERT, 2008, 2009, 2011). Como síntoma del caos cromático que supone la falta de normas específicas para la digitalización del patrimonio, el autor propone un interesante ejercicio: una simple búsqueda en Google de imágenes de cualquier obra de arte conocida, como La creación de Miguel Ángel, sirve para comprobar las diferencias evidentes entre imágenes de una misma obra. Si se traslada esa experiencia a imágenes producidas por museos o, como hemos visto, a algún proyecto de conservación y restauración de hace unos años, no es raro observar el mismo problema. 
En los artículos citados, el autor aboga por la adopción de estándares internacionales en la digitalización de bienes culturales y argumenta su propuesta de elección del espacio de color eciRGBv2. Geffert pone especial énfasis en la necesidad de acordar protocolos comunes que garanticen la fiabilidad y perdurabilidad de la imagen. En ese reto deberían estar implicados los organismos internacionales de normalización, los productores y usuarios de imágenes y la industria de equipos digitales e informáticos. Para aprovechar todo el potencial que aporta el sistema digital, sería imprescindible adoptar esos protocolos de captura y procesado, que necesariamente deberían ser objetivos y rigurosos.

El Rochester Institute of Technology realizó en 2011 un estudio igualmente riguroso, fruto de un simposio en el que se analizaron las prácticas en la reproducción de obras de arte de varias instituciones y museos (FREY; FARNAND, 2011).

\section{Un nuevo enfoque con más precisión}

Habría que destacar iniciativas más ambiciosas, como el programa holandés Metamorfoze, de la Koninklijke Bibliotheek (Biblioteca Nacional de los Países Bajos) y los archivos nacionales, que han dado lugar a las Metamorfoze Preservation Imaging Guidelines (DORMOLEN, 2012), y se están implantando sobre todo en el ámbito europeo. El propósito de estas directrices de digitalización es también la obtención de un archivo máster con espacio de color eciRGBv2, con 8 o 16 bits de profundidad. El flujo de trabajo incorpora unos estrictos criterios de calidad objetivos y de validación de resultados, entre los que están la fidelidad tonal y cromática de la reproducción fotográfica, de forma que se garantiza la preservación y se evita repetir la inversión realizada en su obtención. En principio están destinadas a la digitalización de materiales de dos dimensiones como manuscritos, archivos, libros, periódicos y revistas, siendo aplicables también a la digitalización de fotografías, pinturas y dibujos técnicos; se ha probado su utilidad y consistencia en la reproducción fotográfica del color en objetos tridimensionales.

Un proyecto similar auspiciado por un grupo de agencias federales de EEUU son las Technical Guidelines for Digitizing Cultural Heritage Materials: Creation of Raster Image Master Files, de la Federal Agencies Digitization Initiative (FADGI)-Still Image Working Group (FADGI, 2010). Orientadas principalmente a la digitalización de documentos, el espacio de color recomendado para el archivo máster es AdobeRGB a 8 bits.

La principal aportación de estas dos guías es la incorporación del control de calidad en la obtención de imágenes del patrimonio, con medidas objetivas de captura y fidelidad del color. 


\begin{tabular}{|c|c|c|c|}
\hline IMAGE FORMAT & METAMORFOZE & METAMORFOZE LIGHT & METAMORFOZE EXTRA LIGHT \\
\hline Color accuracy. & Mean $\Delta E^{*} \leq 4$ & Mean $\Delta E^{*} \leq 5$ & Mean $\Delta E^{*} \leq 5$ \\
\hline cie 1976, Digital & $\operatorname{Max} \Delta E^{*} \leq 10$ & $\operatorname{Max} \triangle E^{*} \leq 18$ & $\operatorname{Max} \Delta E^{*} \leq 18$ \\
\hline Colorchecker SG & & & \\
\hline
\end{tabular}

En el protocolo Metamorfoze, la calidad de la imagen digital queda determinada por el cumplimiento de una serie de criterios técnicos. Los valores a tener en cuenta en la fase de digitalización son: espacio de color y profundidad de bit, balance de blancos, rango tonal y exposición. Tras comprobar que la captura tonal ha sido correcta, se pueden evaluar los aspectos de calidad de imagen con las herramientas de análisis: resolución, nivel de ruido, precisión del color, distorsión geométrica y artefactos de imagen. Estos parámetros están relacionados unos con otros y se influyen mutuamente. Por tanto, el orden en el que se aplican es esencial, tanto en el proceso de digitalización como en el análisis de resultados. Para realizar dicho análisis se han desarrollado una carta técnica de referencia (Universal Test Target, UTT) y un software específicos, aunque el sistema es compatible con la carta ColorCheckerSG, que está más extendida en el sector.

Se establecen tres niveles de calidad, cada uno con un margen de tolerancia distinto, que está en función de los originales a digitalizar. Las cartas técnicas de referencia y los equipos fotográficos exigidos también son diferentes para los tres niveles.

El primer nivel es el más exigente en cuanto a la fidelidad del color. Está destinado a la digitalización de originales que son considerados obras de arte, ya sean documentos relevantes, mapas, colecciones fotográficas y pinturas. Es obligado el uso de la carta UTT y exige el empleo de cámaras de alto nivel, como los sistemas de respaldo digital de Hasselblad, Leaf y PhaseOne. La medida de las diferencias de color se establece mediante la fórmula deltaE CIE76, con un margen de tolerancia medio inferior o igual a 4 y máximo de 10.

El archivo máster de preservación debe llevar el espacio de color eciRGBv2. La principal ventaja de este espacio es que está basado en la curva de luminosidad $L^{*}$, por lo que las diferencias tonales están construidas en la forma en que las percibe el ojo humano. De este modo, un gris medio en el original se mantiene como gris medio en la imagen digital, algo que no se da en espacios de color con gamma 2,2 (AdobeRGB, sRGB) o 1,8 (ProPhotoRGB). Como eciRGBv2 es un espacio de color con un punto blanco D50, se considera idóneo para archivos destinados a imprenta. En función del rango dinámico y densidad máxima del original, la profundidad de bit será de 8016 bit (GEFFERT, 2008; DORMOLEN, 2012).
Márgenes de tolerancia en deltaE CIE76 de los distintos niveles de calidad de Metamorfoze | fuente Metamorfoze Guidelines, Creative Commons 


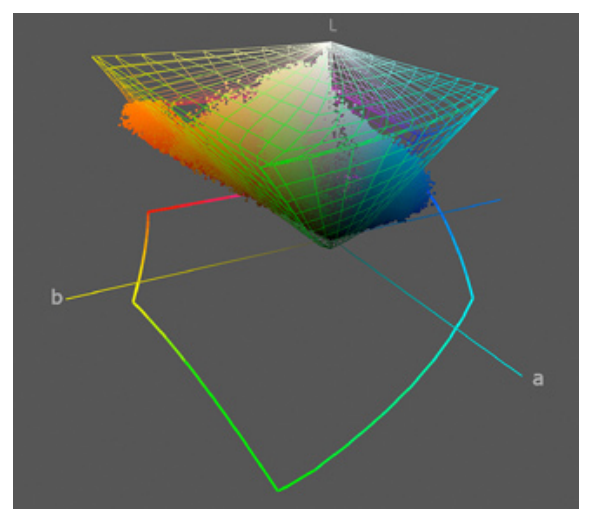

Representación gráfica del espacio de color AdobeRGB en la que se incluyen los colores de la imagen anterior; se aprecian los colores que quedan fuera de gama

Las zonas resaltadas en verde de la imagen de la derecha indican los colores que quedan fuera de la gama del espacio de color AdobeRGB. Detalle del Libro de Regla de la Cofradía de Ntra. Sra. de las Aguas. Iglesia del Divino Salvador, Sevilla
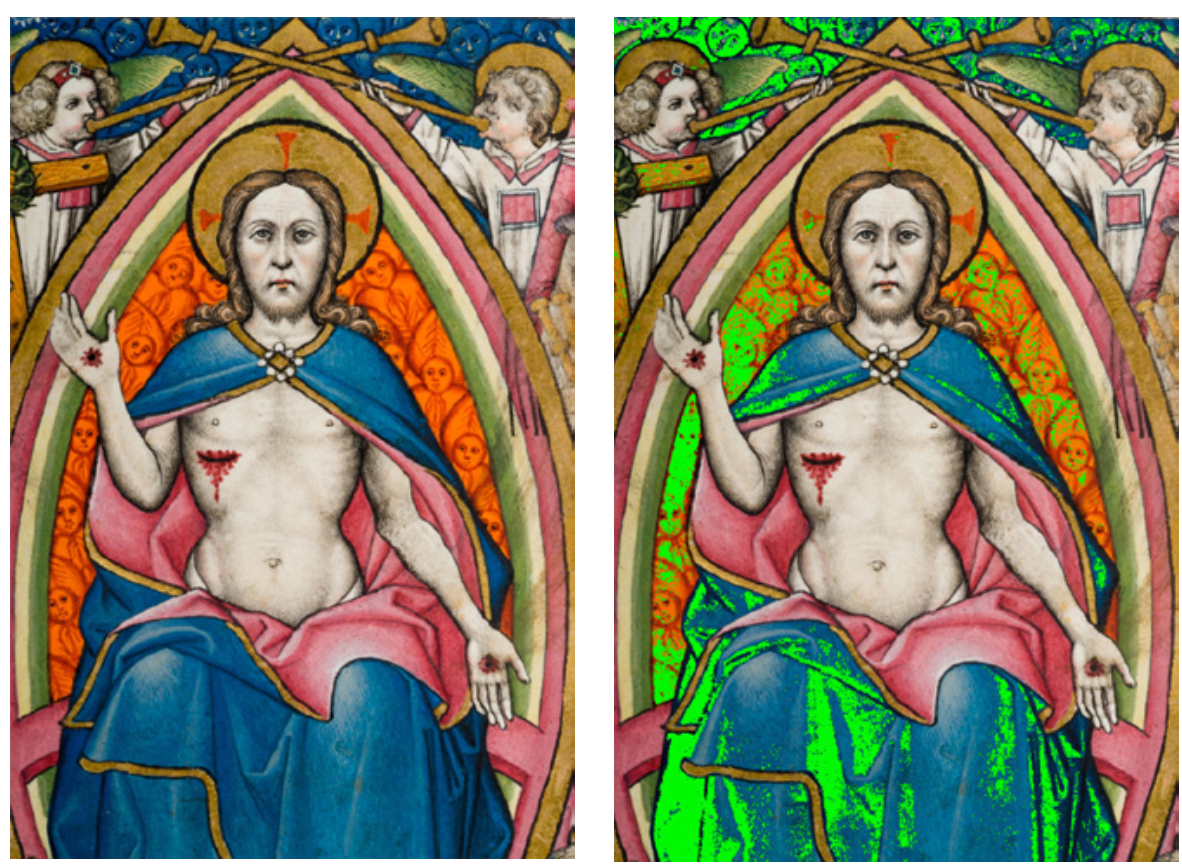

Los otros dos niveles de calidad están destinados a la digitalización de documentos originales manuscritos o impresos, en los que la fidelidad del color sea menos importante o incluso nula (libros impresos o publicaciones periódicas a una tinta).

Hay un consenso casi unánime en la elección del formato TIFF sin compresión como archivo máster de preservación. De este archivo se derivan las copias que sean necesarias en distintos formatos, tamaños o espacios de color, en función del destino que se quiera dar a la imagen (web, imprenta, etc.). La imagen en formato TIFF es una versión definitiva, un producto final editado en un espacio de color que debe llevar incrustado para su correcta lectura. La elección de ese espacio de color y la profundidad de bits del archivo máster es de la máxima importancia.

El espacio AdobeRGB se ha convertido prácticamente en un estándar de facto, y es recomendado en muchas guías como única opción. Sin embargo, es preciso tener en cuenta que su elección debería depender de la gama de tonos y colores de la obra original, que deben de quedar dentro de la gama del espacio de destino. En el ejemplo de la fotografía del detalle de un libro iluminado se puede observar que algunos colores quedan fuera de la gama de AdobeRGB y su referencia cromática se perdería en un TIFF con ese espacio de color. Esta información sólo quedará registrada en un TIFF con un espacio de color más amplio, como ProPhotoRGB; esto obligaría a guardar la imagen con una profundidad de color de 16 bit para evitar problemas de posterización, lo que duplica el tamaño de archivo. 
Obviamente, esta información permanece en el archivo RAW original, que también debe reservarse. En este sentido hay observar que, con vistas a la preservación de la información colorimétrica, no basta con conservar la captura original, es necesario salvaguardar también la información relativa al procesado del RAW y los perfiles utilizados.

De ahí que se esté considerando la adopción del formato abierto DNG como archivo de preservación. El DNG lleva incrustado el perfil de cámara utilizado para su edición y el historial de procesado en programas de Adobe, sin necesidad de una archivo sidecar. Sin embargo, algunas desventajas son la falta de estándar de procesado y su dificultad en comparación con la edición mucho más sencilla de una imagen TIFF.

\section{La experiencia en el Laboratorio de medios físicos de examen}

Desde que iniciara su andadura hace ahora 25 años, el Instituto Andaluz del Patrimonio Histórico tuvo clara la importancia de la fotografía en la documentación del patrimonio cultural andaluz, y comenzó pronto a generar sus propios fondos gráficos. En 1994, la demanda creciente de servicios fotográficos por el Centro de Intervención llevó a la creación de un taller de fotografía "cuya función sería el apoyo a los talleres de restauración mediante la realización de fotografías, radiografías, endoscopias, ultravioletas e infrarrojos" (IAPH, 2010). Este taller pasó a llamarse Laboratorio de medios físicos de examen, LMFE, al incorporar otras técnicas de estudio por la imagen, además de la fotografía. La adaptación a la fotografía digital se inicia en 2004.

A lo largo de esta trayectoria los métodos de reproducción fotográfica se han ido adecuando a los nuevos sistemas, medios y equipos. La experiencia de los primeros años de fotografía digital puso de manifiesto la necesidad de incorporar nuevos flujos de trabajo orientados a la mejora y al control de calidad de los resultados obtenidos, en la línea de las guías de digitalización mencionadas anteriormente. Entre otros factores, sin duda la detección de inconsistencias en proyectos pasados tuvo que ver con eso.

El equipo de captura digital del LMFE consta de varias cámaras DSLR, una de formato completo 24x36 m Nikon D3X, con sensor de $24 \mathrm{Mpx}$ y dos cuerpos Nikon D200, con sensor de $10 \mathrm{Mpx}$, con un completo juego de lentes acorde a la calidad requerida por la cámara de mayor resolución. La captura fotográfica se realiza en formato RAW (NEF de Nikon).

El equipo de iluminación está compuesto por varias unidades de flash electrónico de estudio alimentadas por dos generadores, que proporcionan una potencia controlada y una calidad luminosa aproximada de $5000^{\circ}$ Kelvin, equivalente a la luz día. 
3

Color Analysis para Photoshop: http://www. jpereira.net/color-analysis-4-photoshop
En relación al control de la reproducción del color, se decidió emplear en el proceso la carta ColorChecker Passport, con el fin de introducir una referencia objetiva que permite tanto la creación de perfiles de cámara como la validación de resultados con aplicaciones sencillas. El ajuste tonal se realiza con los grises de la carta ColorChecker, acompañada en ocasiones de una carta de grises Kodak Q13.

El perfilado de cámaras se realiza siguiendo la propuesta de Adobe, con las aplicaciones de creación de perfiles DCP de X-Rite ColorChecker Camera Calibration y Adobe DNG Profile Editor, que se emplea en ocasiones para la edición de los perfiles.

El revelado de los archivos RAW se efectúa con el software Adobe Photoshop Lightroom. El método de trabajo, como se verá, permite conseguir una gran precisión colorimétrica, dentro de los parámetros exigidos por el primer nivel de Metamorfoze. El análisis colorimétrico, basado en los valores de la carta ColorChecker (MYERS, 2010), se realiza con la secuencia de comandos para Photoshop Color Analysis ${ }^{3}$, diseñada por José M. Pereira, que ofrece información de las diferencias de color en términos de deltaE con las fórmulas CIE76 y CIE00.

La calibración de monitores de los equipos informáticos se realiza periódicamente con un espectrofotómetro Xrite Colormunki Photo a través del software proporcionado por el fabricante, que ajusta directamente la tabla interna del monitor.

\section{Metodología}

El proceso que sigue tiene por objeto la obtención de una imagen RAW que sirva de referencia para el perfilado de cámara y para el análisis de resulta-
De izquierda a derecha, imagen en color RGB los tres canales del espacio L* $a^{*} b^{*}$ de la misma imagen. El canal acromático de luminosidad $L^{*}$ es el que contiene la mayor parte de la información visual. Detalle del tapiz Ariadna reina, del Museo de Bellas Artes de Granada

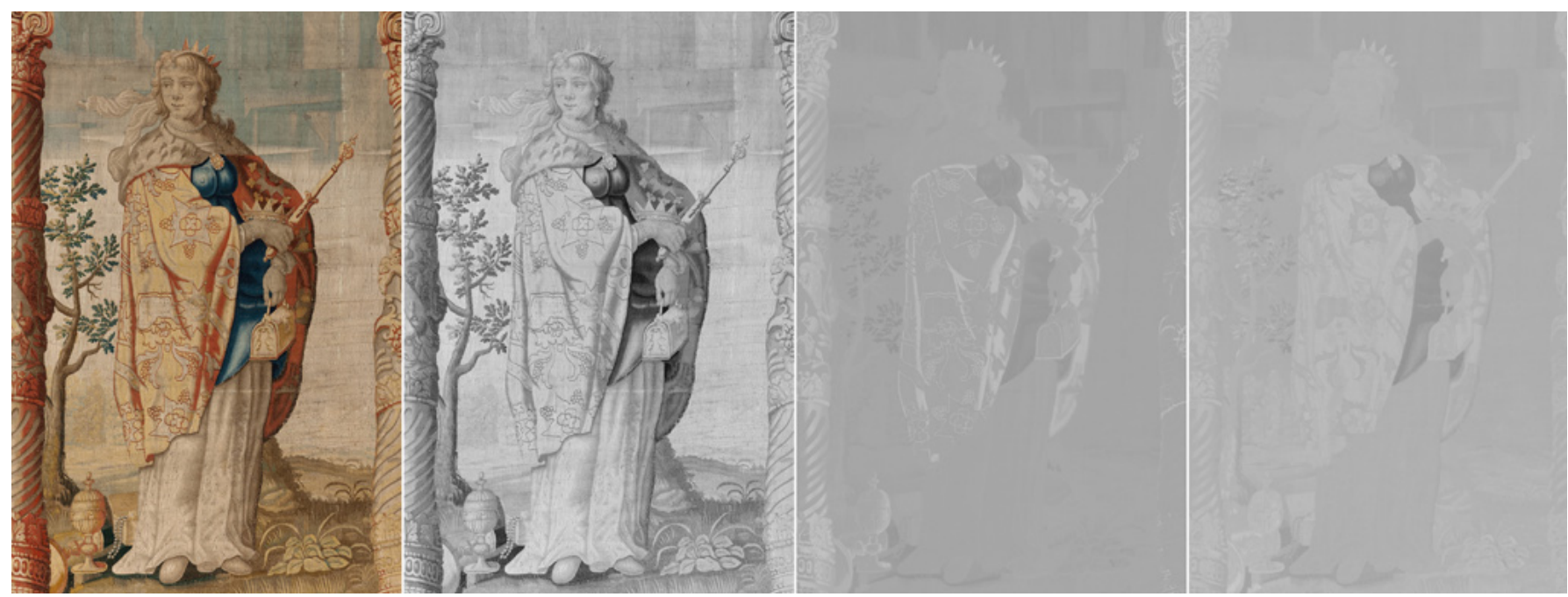


dos. Resumidamente, se realiza la captura de la carta de color, controlando que la exposición es correcta; obtención del perfil de cámara; con el perfil cargado, se realiza un procesado neutro con intención colorimétrica, con ajuste de la escala tonal en función de los valores de los parches grises de la carta; se exporta la imagen con un perfil de gama amplia como ProPhotoRGB a 16 bit; el resultado se analiza con la herramienta Color Analysis; por último, comprobación de la gama de color para la elección del perfil de destino del archivo máster.

\section{Proceso de captura}

El primer paso del proceso de trabajo es la creación de los perfiles de cámaras, de acuerdo con los distintos tipos de iluminación que vayan a emplearse. Se requiere la obtención de una imagen RAW de la carta ColorChecker Passport, que es analizada por el software específico para generar el perfil DCP. En función del programa que se utilice en la creación del perfil, puede ser necesario convertir el archivo RAW en DNG. La captura de la carta se realiza siguiendo el mismo proceso que en los trabajos de digitalización de obras, detallado a continuación.

\section{Balance de blancos}

El balance de blancos se realiza sobre la referencia que incorpora para esta función la carta ColorChecker Passport. Medida con espectrofotómetro, este parche presenta una línea de respuesta espectral prácticamente plana, lo que indica que está libre de dominantes de color. Tiene una reflectancia de alrededor del 60 \% para conseguir una buena relación señal/ruido.

\section{Exposición}

La captura del rango tonal completo que permite un sensor digital requiere partir de una exposición correcta. En fotografía digital la exposición la deter-
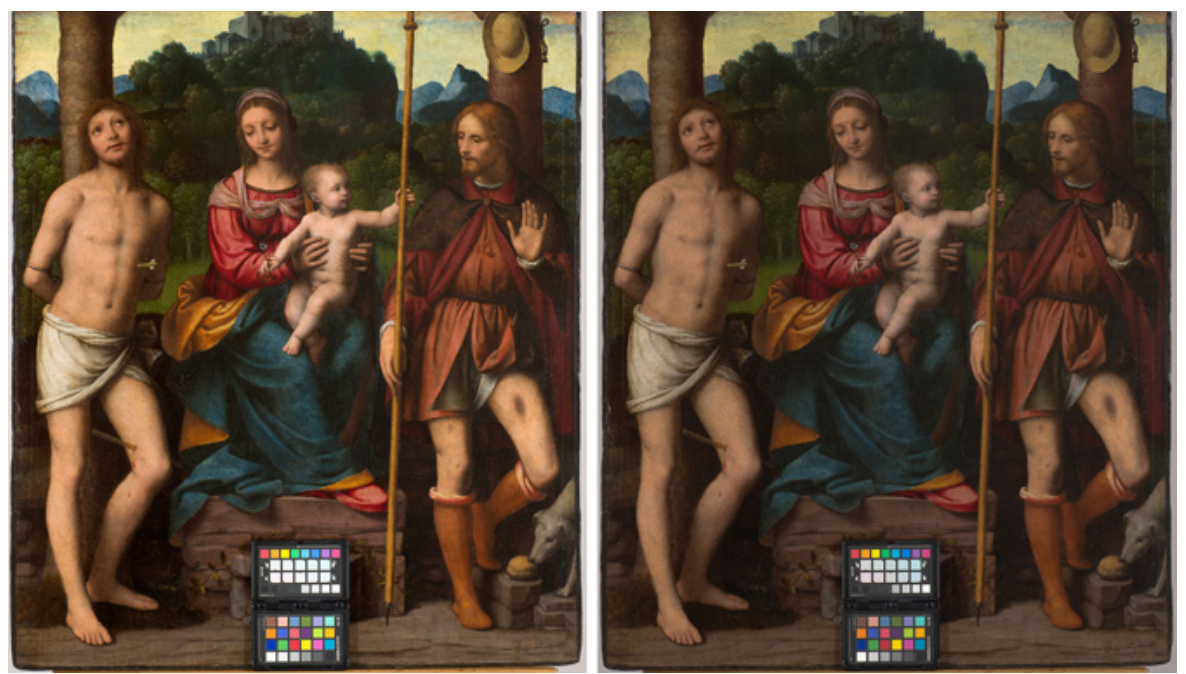

La imagen de la izquierda ha sido ajustada para obtener un resultado perceptualmente agradable; la versión de la derecha está procesada de forma neutra con los valores ajustados a la escala tonal, por lo que el resultado del análisis colorimétrico es más preciso (gráficos p. 120). Pintura sobre tabla Virgen con Niño San Sebastián y San Roque. Iglesia Parroquial de Santa María de la Mesa. Utrera 
4

Puede haber ligeras variaciones en los valores numéricos de las cartas de color, por lo que es recomendable medir las cartas que se usen con espectrofotómetros. Varios autores han publicado referencias a partir de sus propias mediciones. Los valores publicados por el fabricante X-Rite se pueden ver en http://xritephoto.com/ph_product_overview.aspx?ID=12 57\&Action=Support\&SupportID=5159

5

Adobe ha modificado el proceso del motor de revelado de Lightroom y CameraRAW básicamente en tres ocasiones, en 2003, 2010 y 2012. Los dos primeros son similares en la disposición de los diferentes controles, aunque con mejoras notables en el proceso 2010. El cambio más relevante se introdujo en el proceso 2012, en el que cambian los controles principales de exposición y ajuste tonal. Pero la novedad más importante de este último es que incorpora ajustes automáticos de recuperación de altas luces y sombras profundas que no son controlables por el usuario; la curva tonal por defecto se denomina lineal, pero internamente es una curva de contraste en forma de S (EVENING, 2013; SCHEWE, 2013). Estos dos factores hacen que no sea aconsejable el proceso 2012 para conseguir e revelado neutral con intención colorimétrica. minan principalmente las altas luces que se desea que conserven detalle, pudiendo estar referidas a las muestras con tonos neutros claros o blancos de la escala de grises. La exposición debe ser fijada en cámara mediante el diafragma, la velocidad de obturación o el ajuste de la iluminación, no en el procesado con software.

Siguiendo las recomendaciones de la guía Metamorfoze, la exposición se debe basar en la lectura directa de los valores Lab del parche blanco de la escala de grises, aunque pocas cámaras proporcionan esta opción. En su defecto, es conveniente analizar ese valor de la captura RAW en el software de procesado, con los parámetros ajustados para el revelado lineal con intención colorimétrica y el perfil de cámara cargado. Los programas de revelado Lightroom 5, CameraRAW o RAWTherapee permiten leer los valores de color en modo Lab.

El control de la exposición se realiza en función del parche blanco D1 de la ColorChecker, cuyo valor de luminosidad $L^{*}$ es de 96,6. En RGB el valor es alrededor de 250 en AdobeRGB y eciRGBv2 (MYERS, 2010); en Lightroom los datos RGB se expresan en porcentajes, y su correspondencia sería 96,2 según el espacio de trabajo propio de este software ${ }^{4}$.

La carta ColorChecker Passport incluye además una escala de grises adicional destinada a orientar en el ajuste de la exposición mediante la lectura del histograma. Se trata de dos grupos de cuatro parches para controlar las altas y bajas luces, cuya densidad está escalada en pasos de 1/3 EV. Activando en la cámara el indicador de sobreexposición de altas luces, es posible controlar la exposición. Sin embargo, esta información se basa en una imagen procesada internamente, una miniatura JPEG creada sólo con fines de visualización.

El procesado de esa imagen depende de unos parámetros del menú de la cámara que deberían de ajustarse a los valores mínimos de contraste y saturación.

El revelado del archivo RAW obtenido se realiza en Lightroom (proceso 2010) ${ }^{5}$. Para obtener una imagen destinada al análisis colorimétrico, todos los ajustes de tono deben ponerse a cero y la curva en modo lineal; con el perfil de cámara cargado se ajusta el balance de blancos en uno de los parches apropiados. La curva se ajusta por puntos según los valores de los cinco parches gris neutro.

El perfil de cámara no garantiza por sí solo la fidelidad del color. La escala tonal de luminosidad tiene una gran importancia en la imagen digital y, a pesar de ser un componente acromático, influye decisivamente en el color. Una imagen Lab está compuesta de tres canales: un 
canal acromático de luminosidad $L^{*}$ y dos canales cromáticos $a^{*}$ y $b^{*}$. Como se puede apreciar en el ejemplo, la mayor parte de la información visual está contenida en el canal acromático (MACDONALD; JACOBSON, 2006). De ahí que, además del perfil de cámara, sea necesario ajustar la gama tonal en función de una escala de grises para conseguir una colorimetría más precisa.

Es preciso añadir que los ajustes de procesado necesarios para realizar el análisis colorimétrico proporcionan una imagen visualmente plana, falta de contraste y de saturación.

Sin embargo, los datos son claros: la imagen editada de forma subjetiva o con los valores por defecto del programa de revelado es visualmente más agradable, pero proporciona peores resultados colorimétricos.

El análisis colorimétrico realizado con la herramienta Color Analysis de José Pereira, como se aprecia en la tabla, aporta como resultado un deltaE medio CIE76 de 2,63 y máximo de 4,60. Estos valores quedan dentro del umbral de tolerancia exigido en Metamorfoze, marcado con líneas rojas en los gráficos

\begin{tabular}{|c|c|c|c|c|c|c|c|c|c|c|}
\hline & Results & & & ences & & & & & & \\
\hline Sample & L & a & b & L & a & b & $\mathrm{dC}$ & $\mathrm{dH}$ & CIE76 & CIE00 \\
\hline A1 & 40,39 & 13 & 15 & 37,99 & 13,56 & 14,06 & 0,32 & 1,05 & 2,64 & 2,30 \\
\hline A2 & 67,06 & 20 & 14 & 65,71 & 18,13 & 17,81 & 1,00 & 4,12 & 4,45 & 3,52 \\
\hline A3 & 49,8 & -6 & -24 & 49,93 & $-4,88$ & $-21,93$ & 2,27 & 0,63 & 2,36 & 1,38 \\
\hline A4 & 44,31 & -14 & 24 & 43,14 & $-13,1$ & 21,91 & 2,25 & 0,34 & 2,56 & 1,51 \\
\hline A5 & 54,12 & 8 & -26 & 55,11 & 8,84 & $-25,4$ & 0,31 & 0,98 & 1,43 & 1,38 \\
\hline A6 & 69,02 & -34 & -4 & 70,72 & $-33,4$ & $-0,2$ & 0,83 & 3,76 & 4,21 & 2,85 \\
\hline B1 & 64,31 & 38 & 58 & 62,66 & 36,07 & 57,1 & 1,80 & 1,15 & 2,70 & 1,61 \\
\hline B2 & 39,22 & 11 & -49 & 40,02 & 10,41 & $-45,96$ & 3,10 & 0,00 & 3,20 & 1,25 \\
\hline B3 & 53,33 & 50 & 16 & 51,12 & 48,24 & 16,25 & 1,60 & 0,78 & 2,84 & 2,28 \\
\hline B4 & 30,59 & 22 & -20 & 30,33 & 22,98 & $-21,59$ & 1,80 & 0,52 & 1,89 & 0,87 \\
\hline B5 & 72,16 & -24 & 54 & 72,53 & $-23,71$ & 57,26 & 2,88 & 1,55 & 3,29 & 1,17 \\
\hline B6 & 70,59 & 17 & 69 & 71,94 & 19,36 & 67,86 & 0,49 & 2,58 & 2,95 & 1,90 \\
\hline $\mathrm{C} 1$ & 25,1 & 12 & -52 & 28,78 & 14,18 & $-50,3$ & 1,11 & 2,52 & 4,60 & 3,52 \\
\hline $\mathrm{C} 2$ & 56,86 & -38 & 28 & 55,26 & $-38,34$ & 31,37 & 2,34 & 2,45 & 3,75 & 2,07 \\
\hline C3 & 44,71 & 52 & 26 & 42,1 & 53,38 & 28,19 & 2,23 & 1,31 & 3,67 & 2,60 \\
\hline C4 & 81,57 & 1 & 79 & 81,73 & 4,04 & 79,82 & 0,91 & 3,01 & 3,15 & 1,76 \\
\hline C5 & 52,16 & 50 & -13 & 51,94 & 49,99 & $-14,57$ & 0,41 & 1,51 & 1,58 & 0,75 \\
\hline C6 & 49,41 & -27 & -32 & 51,04 & $-28,63$ & $-28,64$ & 1,37 & 3,47 & 4,07 & 2,46 \\
\hline D1 & 96,08 & -1 & 0 & 96,54 & $-0,43$ & 1,19 & 0,27 & 1,29 & 1,40 & 1,45 \\
\hline D2 & 80,78 & -1 & -1 & 81,26 & $-0,64$ & $-0,34$ & 0,69 & 0,30 & 0,89 & 0,87 \\
\hline D3 & 66,27 & -1 & -1 & 66,77 & $-0,73$ & $-0,5$ & 0,53 & 0,19 & 0,75 & 0,73 \\
\hline D4 & 50,59 & -2 & -1 & 50,87 & $-0,15$ & $-0,27$ & 1,93 & 0,49 & 2,01 & 2,68 \\
\hline D5 & 36,08 & -2 & -1 & 35,66 & $-0,42$ & $-1,23$ & 0,94 & 1,29 & 1,65 & 2,24 \\
\hline D6 & 20,78 & 0 & -2 & 20,46 & $-0,08$ & $-0,97$ & 1,03 & 0,02 & 1,08 & 1,00 \\
\hline \multicolumn{7}{|l|}{ Average } & 1,35 & 1,47 & 2,63 & 1,84 \\
\hline
\end{tabular}




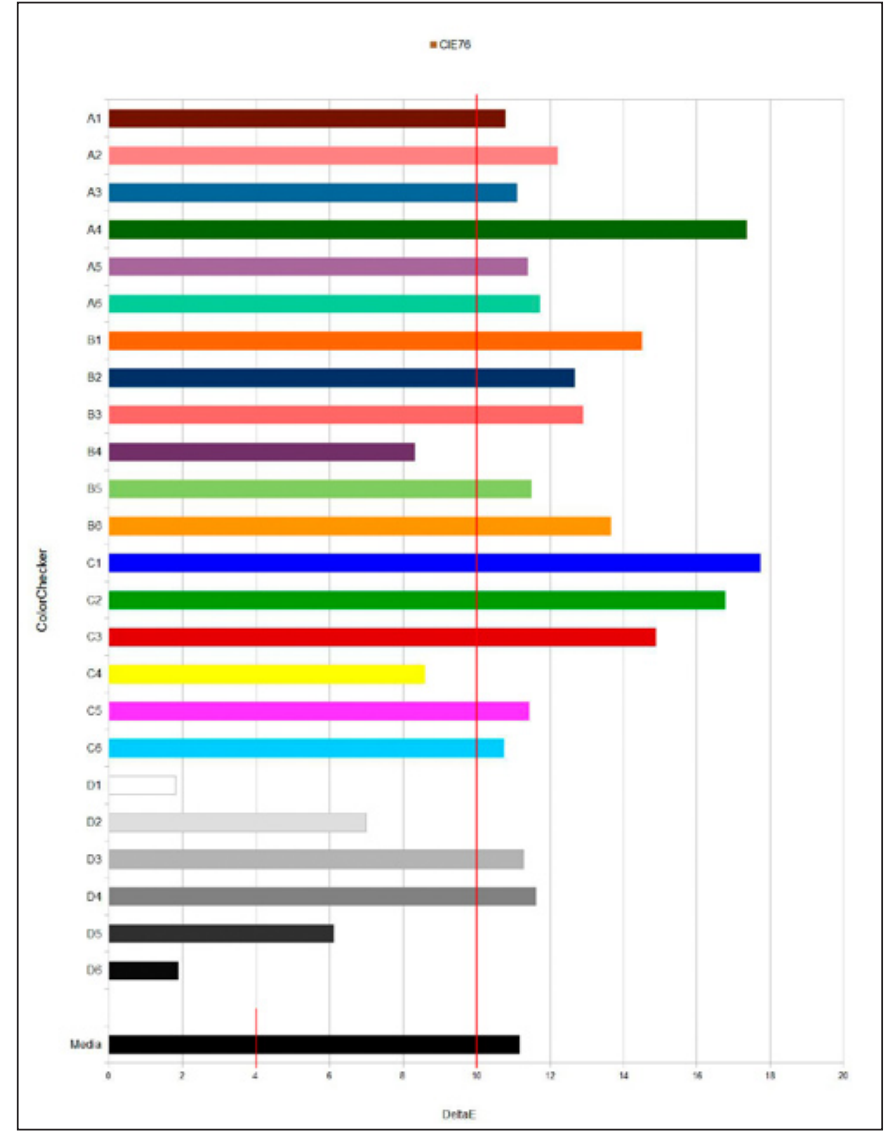

Gráfico de resultados deltaE de la imagen izquierda de la página 117

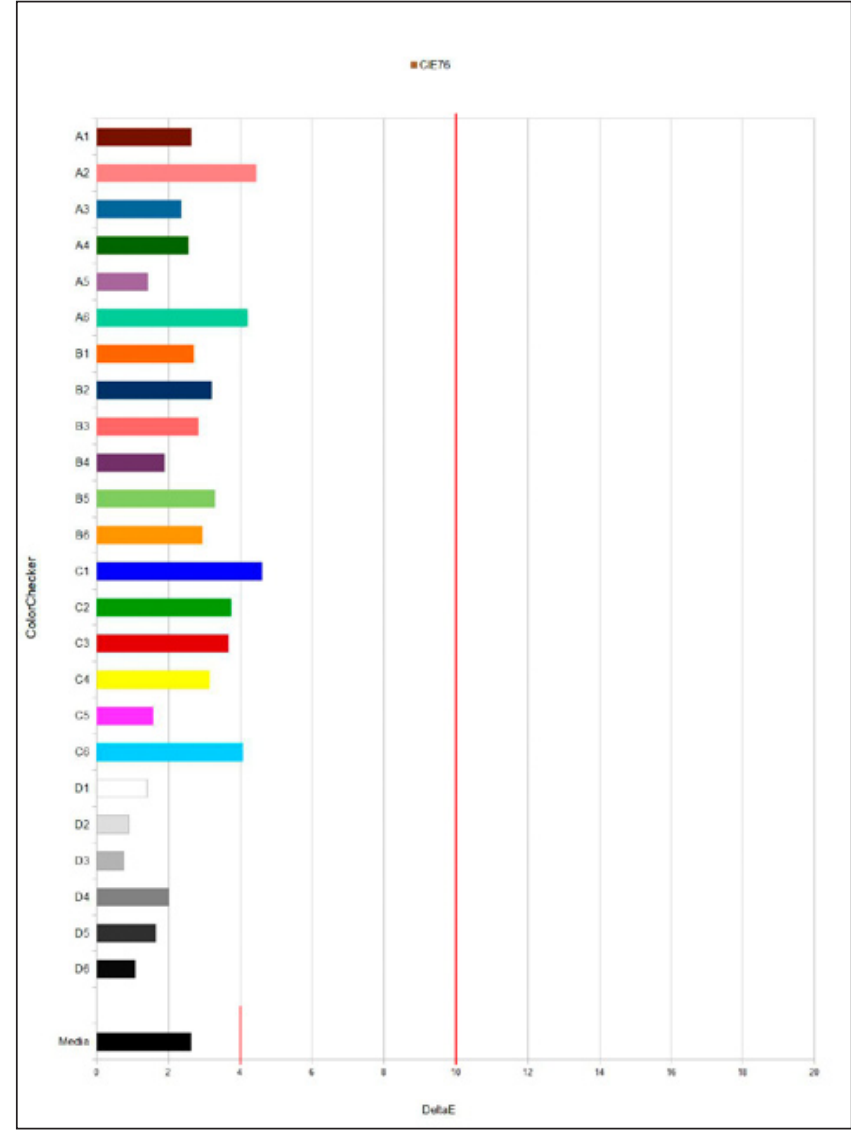

Gráfico de resultados deltaE de la imagen derecha de la página 117

\section{CONCLUSIONES Y RETOS PENDIENTES}

Con una metodología precisa y herramientas sencillas al alcance de todos, la fotografía digital puede servir de salvaguarda de la información colorimétrica, lo que resulta un valor añadido en su utilización como instrumento de preservación del patrimonio.

Se ha podido comprobar que, siguiendo un sencillo protocolo, los valores colorimétricos medidos en cartas quedan dentro de unos márgenes razonables, al nivel de las directrices más exigentes. Algunos test realizados con probetas de pigmentos al óleo han proporcionado también buenos resultados, pero está en proceso de diseño un ensayo riguroso.

El siguiente reto sería extender el control de calidad a otros parámetros, como la medida del rango dinámico de las cámaras, la resolución de imagen o el control de la uniformidad de iluminación, que puede presentar dificultades en obras de grandes dimensiones tanto como pinturas como tapices. 

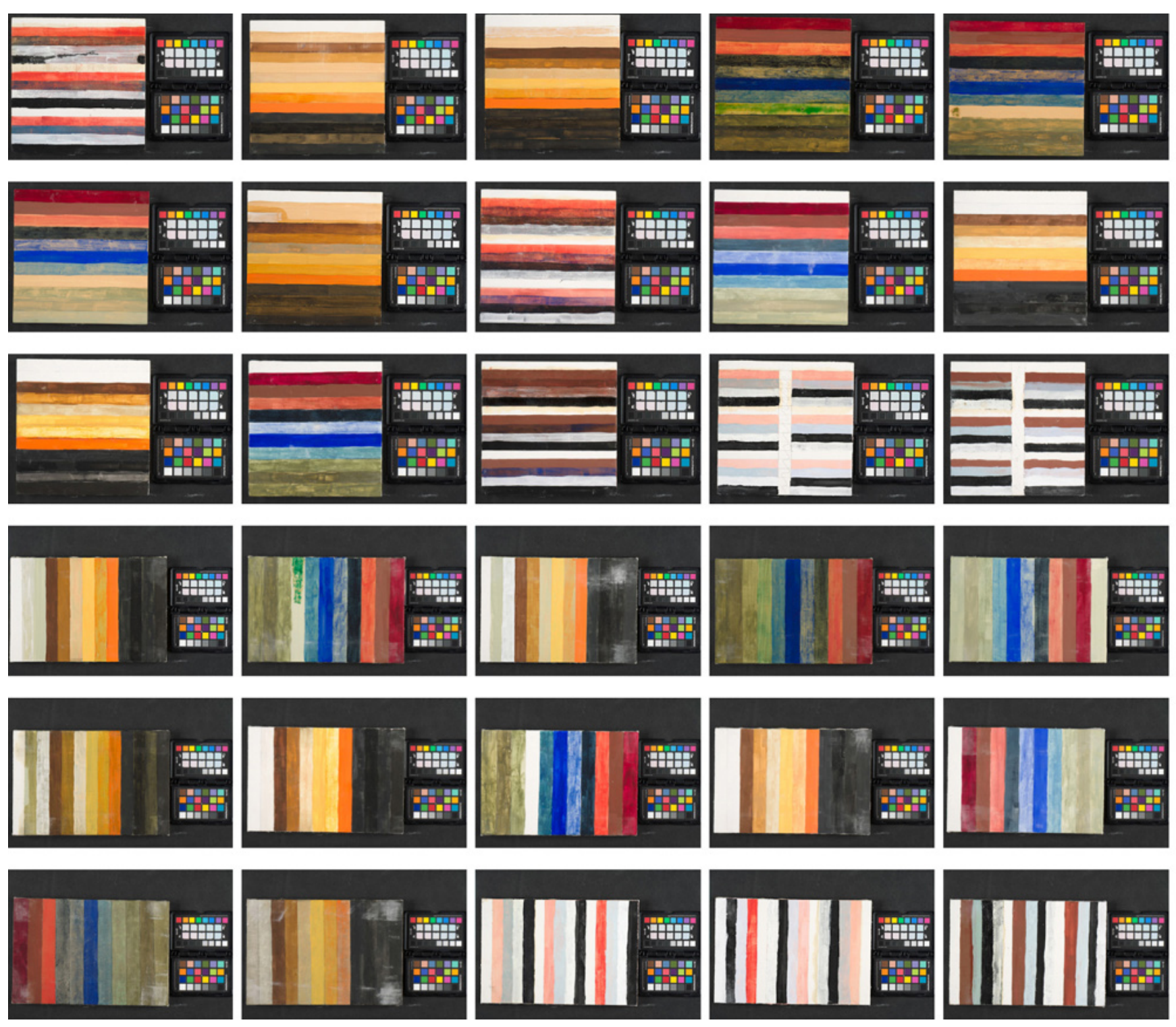

Probetas de color

Por último, es necesario consensuar los factores que atañen al almacenamiento de las fotografías digitales y los elementos implicados en su creación: sistemas de procesado, espacios de color, perfiles de cámara y metadatos relacionados con la edición de la imagen. 


\section{BIBLIOGRAFÍA}

- ADAMS, A. (1997; 1999; 2002) Trilogía fotográfica: La Copia; El Negativo; La Cámara. Madrid: Omnicon, 1997; 1999; 2002

- ADOBE (2012) Digital Negative Specification Version 1.4.0 [en línea] Adobe Systems Incorporated, $2012<$ http:// wwwimages.adobe.com/content/dam/Adobe/en/products/ photoshop/pdfs/dng_spec_1.4.0.0.pdf> [Consulta: 19/06/ 2014]

- BERNS, R. (2005) Color-accurate image archives using spectral imaging. Scientific Examination of Art: Modern Techniques in Conservation and Analysis. National Academies Press, vol. 90, n. ${ }^{\circ}$ 1, pp. 105-119, 2005

- DIRECTRICES para proyectos de digitalización de colecciones y fondos de dominio publico, en particular para aquellos custodiados en bibliotecas y archivos, 2002 [en línea] Ministerio de Cultura, 2002 (apéndices actualizados a 13 de junio de 2014) <http://hdl.handle.net/10421/3342 > [Consulta: 19/06/2014]

- DORMOLEN, H. VAN (2012) Metamorfoze Preservation Imaging Guidelines. Image quality, version 1.0 [en línea] National Lybrary of the Netherlands, $2012<$ <ttp://www. metamorfoze.nl/sites/metamorfoze. nl/files/publicatie documenten/Metamorfoze_Preservation_Imaging Guidelines_1.0.pdf> [Consulta: 19/06/2014]

- EVENING, M. (2013) The Adobe Photoshop Lightroom 5 Book. The Complete Guide for Photographers. Adobe Press, 2013

- FADGI (2010) Technical Guidelines for Digitizing Cultural Heritage Materials: Creation of Raster Image Master Files [en línea]. Federal Agencies Digitization Initiative (FADGI)-Still Image Working Group, $2010<$ http://www. digitizationguidelines.gov/guidelines/FADGI_Still_ImageTech_Guidelines_2010-08-24.pdf> [Consulta: 19/06/2014]

- FRASER, B.; MURPHY, C.; BUNTING, F. (2005) Real World Color Management. 2. ${ }^{\mathrm{a}}$ ed. Berkeley: Peachpit Press, 2005

- FREY, F. S.; FARNAND, S. (2011) Benchmarking Art Image Interchange Cycles. Final Report [en línea] Rochester Institute of Technology, $2011<$ <ttp:// artimaging.rit.edu/wordpress/wp-content/uploads/2011/07/ MellonFinalReport_FreyFarnand.pdf> [Consulta: 19/06/ 2014]

- FUENTES DE CÍA, A. M. (2000) La conservación de la fotografía en color. Una urgente necesidad [en línea]. Image i ReÇerca. 6a Jornades Antoni Varés. Girona. $2000<$ http:// www.angelfuentes.es/PDF/Vares_2000.pdf> [Consulta: 19/ 06/2014]

- FUENTES DE CÍA, A. M. (2012) La conservación de archivos fotográficos [en línea]. SEDIC, Asociación
Española de Documentación e Información, $2012<$ <ttp:// www.sedic.es/DT-n3-SEDIC-Conservacion.pdf> [Consulta: 19/06/2014]

- GEFFERT, S. (2008) Adopting ISO Standards for Museum Imaging [en línea]. Center for Digital Imaging, Inc., 2008 <http://www.imagingetc.com/images/Resources_Images/ PDFs DownloadFiles/ISO\%20Standards\%20for\%20Muse um\%20Imaging_cdi_v1.0.pdf> [Consulta: 19/06/2014]

- GEFFERT, S. (2009) Implementing Imaging Standards: The Longest Yard [en línea]. Imagingetc Inc., 2009 <http://www.imagingetc.com/images/Resources Images/ PDFs_DownloadFiles/Implementing\%20Imaging\%20St andards_the\%20Longest\%20Yard_Final.pdf> [Consulta: 19/06/2014]

- GEFFERT, S. (2011) Transitioning to International Imaging Standards at the Metropolitan Museum of Art: A Case Study [en línea]. Imagingetc Inc., $2011<$ http:// www.imagingetc.com/images/Resources_Images/PDFs DownloadFiles/Transitioning\%20to\%20International\%20St andards.pdf> [Consulta: 19/06/2014]

- GREEN, P. (2006) Colour Management in Heritage Photography. En MACDONALD, L. (ed.) Digital Heritage. Applying Digital Imaging to Cultural Heritage. Burlington: Elsevier, 2006

- IAPH (2010) 1989-2009. 20 Años de IAPH. Sevilla: Instituto Andaluz del Patrimonio Histórico, 2010

- ICC (2005) Digital photography color management basics [en línea] White paper, n. ${ }^{\circ} 20$. International Colour Consortium, $2005<$ http://www.color.org/ICC white paper 20_Digital_photography_color_management_basics.pdf> [Consulta:19/06/2014]

- MACDONALD, L. (ed.) (2006) Digital Heritage. Applying Dogital Imaging to Cultural Heritage. Burlington: Elsevier, 2006.

- MACDONALD, L.; JACOBSON, R. (2006) Assessing Image Quality. En MACDONALD, L. (ed.) Digital Heritage. Applying Dogital Imaging to Cultural Heritage. Burlington: Elsevier, 2006

- MONDENARD, A. DE (1997) La Mission héliographique: mythe et histoire [en línea] Études photographiques, 2, 1997 $<$ http://etudesphotographiques.revues.org/127> [Consulta: 19/06/2014]

- MYERS, R. D. (2010) ColorChecker Passport Technical Review [en línea]. <http://www.rmimaging.com/information/ ColorChecker_Passport_Technical_Report.pdf> [Consulta: 19/06/2014]

- PEREIRA, J. M. (2013) Gestión del color en proyectos de digitalización. Barcelona: Marcombo, 2013 
- RODNEY, A. (2005) Color Management for Photographers. USA: Elsevier, 2005

- SATANCO, F.; BATTIATO, S.; GALLO, G. (2011) Digital Imaging for Cultural Heritage Preservation Analysis, Restoration, and Reconstruction of Ancient Artworks [ebook]. New York: CRC Press, 2011

- SAUNDERS, D.; CUPITT, J.; PADFIELD, J. (2006) Digital Imaging for Easel Paintings. En MACDONALD, L. (ed.) Digital Heritage. Applying Dogital Imaging to Cultural Heritage. Oxford: Elsevier, 2006

- SCHEWE, J. (2013) The Digital Negative: Raw image processing in Lightroom, Camera Raw, and Photoshop. San Francisco: Peachpit Press, 2013

- WHEELER, F. B.; BENNETT, M. J. (2010) RAW as Archival Still Image Format: A Consideration. UConn Libraries Published Works, 2010, paper 23 [en línea]. <http://digitalcommons.uconn.edu/libr_pubs/23> [Consulta: 19/06/2014]

- WHEELER, F. B.; BENNETT, M. J. (2011) Accurate Color? A Preliminary Investigation into the Color Gamut of Selected Special Collection Library Objects. UConn Libraries Published Works, 2011, paper 37 [en línea]. <http://digitalcommons.uconn.edu/libr_pubs/37> [Consulta: 19/06/2014]

- X-RITE (2002) Guía para entender la comunicación del color. X-Rite Incorporated, 2002 